\title{
Capsule Commentary on Thomas et al., A Comparison of the Willingness of Resident and Attending Physicians to Comply with the Requests of Patients at the End of Life
}

\author{
Deanna L. Hill, MD, Lynette Cederquist, MD, and Neil J. Farber, MD \\ Division of General Internal Medicine, University of California San Diego, San Diego, CA, USA.
}

J Gen Intern Med 29(7):1058

DOI: $10.1007 / \mathrm{s} 11606-014-2863-4$

(c) Society of General Internal Medicine 2014

$\mathrm{T}$ his interesting study by Thomas et. al. ${ }^{1}$ explored differences in resident and physician attitudes regarding honoring patient wishes at the end of life. They conducted a survey to assess willingness to honor end-oflife requests in five different clinical scenarios. They found that attendings were significantly more willing to comply with patient requests, and concluded that this was due to clinical experience.

There are several complicating factors, however. Attending demographics varied greatly from the residents. It is not clear that these factors were accounted for in their multivariate model. It is possible that the differences seen between attendings and residents were not due to clinical experience, but rather due to other variables such as religion, race, or gender. Previous studies have shown that physician characteristics influence their opinions as well as their practice. ${ }^{2}$

They also concluded that substantial changes in attitudes occur over the years of residency training. It is unknown what end-of-life training is included in these residency training programs or what training the attendings had. A study from early 2000 found that only $36 \%$ of practicing internists surveyed had training in end-of-life care. ${ }^{3}$ A lack of understanding of the ethical issues surrounding end-oflife care can lead physicians to disagree about ethically appropriate responses to patient requests.

It is not clear why the authors included a question regarding active euthanasia. It would have been more interesting for the authors to explore attitudes regarding active euthanasia. ${ }^{4}$
We need to be cautious about extending this study more broadly. This study only looked at physicians in Connecticut, and practice patterns and attitudes may vary in different geographic regions. The scenarios also only addressed inpatients, and decision making may be different for physicians who have an established outpatient relationship with a patient. Further focus on end-of-life training during residency is needed to ensure that future physicians are better equipped to manage patients at the end of life. Studies to evaluate how exposure to such training influences attitudes regarding treatment choices at the end of life will be useful.

Conflict of Interest: The authors have no conflicts of interest with the material in this manuscript.

Corresponding Author: Neil J. Farber, MD; Division of General Internal Medicine, University of California San Diego, San Diego, CA, USA (e-mail: nfarber@ucsd.edu).

\section{REFERENCES}

1. Thomas JM, O'Leary JR, Fried, TR. A Comparison of the Willingness of Resident and Attending Physicians to Comply with the Requests of Patients at the End of Life. J Gen Intern Med. 2014. doi:10.1007/ s11606-014-2830-0.

2. Christakis NA, Asch DA. Physician characteristics associated with decisions to withdraw life support. Am J Publ Health. Mar 1995;85(3):367-372.

3. Farber NJ, Simpson P, Salam T, Collier VU, Weiner J, Boyer EG. Physicians' decisions to withhold and withdraw life-sustaining treatment. Arch Intern Med. 2006;166(5):560-564.

4. Bushwick B, Emrhein D, Peters K. A Comparison of resident and faculty attitudes toward physician-assisted suicide and active voluntary euthanasia. Fam Med. Apr 2000;32(4):261-266. 